\title{
Position article and guidelines 2018 recommendations of the Brazilian Society of Rheumatology for the indication, interpretation and performance of nailfold capillaroscopy
}

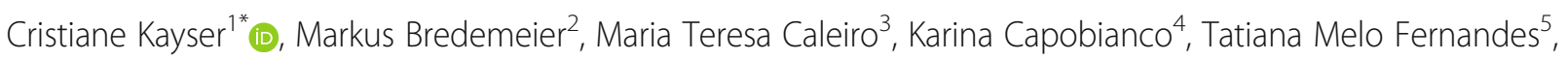 \\ Sheila Márcia de Araújo Fontenele ${ }^{6}$, Eutilia Freire ${ }^{7}$, Lilian Lonzetti ${ }^{8}$, Renata Miossi ${ }^{3}$, Juliana Sekiyama ${ }^{9}$ and \\ Carolina de Souza Müller ${ }^{10}$
}

\begin{abstract}
Nailfold capillaroscopy (NFC) is a reproducible, simple, low-cost, and safe imaging technique used for morphological analysis of nail bed capillaries. It is considered to be extremely useful for the investigation of Raynaud's phenomenon and for the early diagnosis of systemic sclerosis (SSC). The capillaroscopic pattern typically associated with SSc, scleroderma ("SD") pattern, is characterized by dilated capillaries, microhemorrhages, avascular areas and/or capillary loss, and distortion of the capillary architecture. The aim of these recommendations is to provide orientation regarding the relevance of NFC, and to establish a consensus on the indications, nomenclature, the interpretation of NFC findings and the technical equipments that should be used. These recommendations were formulated based on a systematic literature review of studies included in the database MEDLINE (PubMed) without any time restriction.
\end{abstract}

Keywords: Capillaroscopy, Systemic sclerosis, Raynaud's phenomenon

\section{Introduction}

The microcirculation plays a crucial role in physiological processes. Comprising arterioles, capillaries, and venules, it is involved in thermoregulation, hemodynamic balance maintenance, the nutrient supply to cells, and removal of catabolites derived from cell metabolism. The capillary loops are vessels with a small diameter and are usually composed of one single layer of endothelial cells.

Nailfold capillaroscopy (NFC) is a reproducible, simple, low-cost, and noninvasive imaging technique that is used for morphological and functional analyses of the peripheral microcirculation. Because the microcirculation might be the primary site of abnormalities,

\footnotetext{
* Correspondence: cristiane.kayser@unifesp.br

${ }^{1}$ Rheumatology Division, Escola Paulista de Medicina, Universidade Federal de São Paulo (UNIFESP), Rua Botucatu 740, $3^{\circ}$ andar, São Paulo, SP 04023-062, Brazil

Full list of author information is available at the end of the article
}

NFC is used for the diagnosis and evaluation of systemic sclerosis (SSc) spectrum disorders and for the differentiation between primary and secondary Raynaud's phenomenon (RP) [1]. Capillaroscopy evaluation of individuals with RP might contribute to the identification of an underlying disease, as well as to the assessment of disease progression [2-5]. Table 1 describes the main indications of NFC in rheumatology.

Although the role of NFC in the investigation of patients with RP and in the diagnosis of SSc is well established, different magnification equipment and a variety of definitions are used to describe the capillary morphology. In addition, there is no consensus on the parameters that should be analyzed or on the nomenclature to be used. These facts underscore the need to standardize the nomenclature, the indications and interpretation of NFC

(C) The Author(s). 2019 Open Access This article is distributed under the terms of the Creative Commons Attribution 4.0 International License (http://creativecommons.org/licenses/by/4.0/), which permits unrestricted use, distribution, and reproduction in any medium, provided you give appropriate credit to the original author(s) and the source, provide a link to the Creative Commons license, and indicate if changes were made. The Creative Commons Public Domain Dedication waiver (http://creativecommons.org/publicdomain/zero/1.0/) applies to the data made available in this article, unless otherwise stated. 
Table 1 Main indications of capillaroscopy in rheumatology

Evaluation of individuals with Raynaud's phenomenon (RP)

Dermatomyositis (DM)

Mixed connective tissue disease (MCTD)

Systemic sclerosis (SSc)

findings and the technical equipment used to perform NFC [6].

The present recommendations were formulated to provide an orientation on the relevance, indications, technical equipment, nomenclature and the parameters that should be evaluated by NFC in rheumatology practice.

\section{Methods}

The present guidelines followed the criteria developed for systematic reviews. Evidence was collected according to an evidence-based medicine approach, which integrates clinical experience with the ability to critically analyze and rationally apply scientific information, thus improving the quality of medical care. The relevant clinical questions were formulated as per the PICO strategy (acrostic stands for "Patient," "Intervention," "Control," and "Outcome") by the authors, who are all professionally involved in performing nailfold capillaroscopy. The evidence to answer the clinical questions was collected according to the following steps: formulation of clinical questions, structuration of questions, search for evidence, critical evaluation and selection of evidence, presentation of results, and recommendations.

The formulation of structured questions allowed us to identify descriptors that served as a basis in the search for evidence in the MEDLINE-PubMed database. The abstracts of all the retrieved studies were analyzed. Following the application of eligibility (inclusion/exclusion) criteria, articles were selected to answer the questions, which led to the evidence forming the basis of the present guidelines. A manual search of the references cited in (narrative and systematic) reviews and selected studies was also performed. In addition, the references were manually updated until December 2017. The studies were categorized by grades of recommendation and strength of evidence according to the Oxford and GRADE classification systems, as shown in Table 2. The detail of the methods and results are described in the Additional file 1.

\section{Results}

What are the main indications of CAPILLAROSCOPY for rheumatic diseases?

Raynaud's phenomenon (RP)

$\mathrm{RP}$ is characterized by episodes of transient ischemia of the extremities, usually in response to cold or stress $[7,8]$. It presents as a characteristic "triphasic" color pattern change, (pallor, cyanosis, and rubor) of the hands and feet. Population-based studies, which included several ethnic groups, estimated its prevalence as 3 to $20 \%$ as a function of the geographical location and local climate [7-11]. RP is classified as primary, or idiopathic, and secondary.

Primary RP manifests usually in young individuals (14 years of age, on average) and presents as symmetric and milder episodes, without necrosis, ulceration, or gangrene, in addition to the absence of any definite cause $[1,12]$. In turn, secondary RP manifests in adults (generally $\geq 30$ years old); episodes are more intense, painful, and associated with ischemic skin lesions that exhibit signs of microvascular abnormalities. Secondary RP is a common manifestation of autoimmune diseases, such as $\mathrm{SSc}$, mixed connective tissue disease (MCTD), systemic lupus erythematosus (SLE), Sjögren's syndrome, dermatomyositis, and polymyositis [10, 11].

Investigations of RP by means of NFC are widely reported in the literature (B) [10] (D) [12]. NFC is an important method for the early detection of secondary RP and might further contribute to the characterization of clinical aspects and progression of the underlying disease (B) [13]. Several studies have found that the presence of abnormalities in the nailfold microcirculation on NFC is an independent risk factor for the development of autoimmune rheumatic disease $(\mathbf{B})[14,15]$.

A prospective study found that $20 \%$ of patients initially diagnosed with primary RP exhibited a transition to suspected or definite secondary RP during a 10-year follow-up (B) [16]. The frequency of such transitions might vary depending on the analyzed population $(\mathbf{C})$ [17-19]. Another study conducted with 639 patients with primary RP found that $12.6 \%$ of the sample progressed into secondary RP after a mean time of 10.4 years. The main predictor of transition was an abnormal nailfold capillary pattern on NFC, with a positive predictive value of $47 \%$ (A) [17]. Based on the pattern assessed on nailfold videocapillaroscopy, $14.9 \%$ of patients $(n=19)$ in another prospective study were classified as secondary RP over a follow-up period of $29 \pm 10$

Table 2 Grade of recommendation and strength of evidence

\begin{tabular}{ll}
\hline A: & Experimental or observational studies with better consistency \\
B: & Experimental or observational studies with less consistency \\
C: & Case reports/uncontrolled studies \\
D: & Opinions without critical evaluation, based on consensus, physiological studies, or animal models \\
\hline
\end{tabular}


months. Interestingly, $4.6 \%$ of these patients exhibited a normal microcirculation pattern on NFC at the onset of the study (B) [18].

Finally, a study of adults with a history of isolated RP demonstrated, by means of a prognostic model, a correlation between abnormalities on NFC (microhemorrhages, giant loops, and number of capillaries) and progression into SSc spectrum disorders (B) [19].

\section{Systemic sclerosis (SSC)}

SSc is an autoimmune disease of unknown origin characterized by progressive vascular involvement, with subsequent chronic damage of several organs and systems, such as the gastrointestinal tract, lungs, heart, kidneys, and skin [20-22]. Due to its high morbidity and mortality, countless efforts have been devoted in recent years aiming at early diagnosis and early treatment of the disease, before organ damage becomes irreversible [23].

Typical microangiopathy in SSc includes dilated loops, giant loops, a reduced number of loops and avascular areas, microhemorrhages, neoangiogenesis and disorgani zation of the nailfold capillary architecture, which together are known as the "SD" (scleroderma) pattern (B) [24], (C) [25]. The "SD" pattern is found in 80 to $90 \%$ of SSc cases and also occurs in other autoimmune rheumatic diseases [26, 27].

These abnormalities might occur in the early stages of SSc, when the clinical manifestations are restricted to isolated RP. Progressive capillary loss is characteristic of the microvascular dysfunction in SSc and is associated with a higher disease severity (B) [28-30]. A study conducted with SSc patients found that the severity of organ involvement, such as the lungs, skin, and heart, was directly correlated to the pattern of microcirculation damage (B) [28]. Thus, NFC seems to be useful for clinical staging and to obtain prognostic information.

\section{Dermatomyositis}

Capillaroscopic findings in dermatomyositis characteristically include a reduction of capillary loops, dilated capillary loops, remarkably branched loops, and disorganization of the capillary architecture $(\mathbf{C})[31,32]$. The typical "SD" pattern found in SSc exhibits variable rates (B) [33], (C) [32]. Capillaroscopic abnormalities are associated with the activity and severity of disease and interstitial lung involvement (B) [33]. Loop reduction is associated with the global activity of disease and hemorrhage with skin activity (B) [33].

\section{Systemic lupus erythematosus (SLE)}

The main abnormalities found on NFC among SLE patients are increased capillary tortuosity, elongated loops, focal areas of capillary loss, and increased visibility of the subpapillary venous plexus. Capillary rarefaction and dilated loops are correlated with lung involvement $(\mathbf{C})$ [34]. NFC abnormalities are more frequent among patients with SLE and RP (B) [35].

\section{Mixed connective tissue disease (MCTD)}

Several microcirculation abnormalities have been described among patients with MCTD, such as microhemorrhages and capillary disorganization. The pattern on NFC is similar to that of SSc; however, capillary rarefaction and giant capillaries are less frequent in MCTD (C) [36, 37].

\section{Recommendation 1}

Nailfold capillaroscopy is a method for the assessment of the microcirculation and represents a reliable tool for differential diagnosis between primary and secondary Raynaud's phenomenon.

The inclusion of NFC in examinations of patients with Raynaud's phenomenon is recommended to support or rule out its association with systemic sclerosis spectrum disorders, dermatomyositis, and mixed connective tissue disease.

\section{What equipment might be used to perform CAPILLAROSCOPY?}

By means of an optical magnification device and incident light, NFC enables direct evaluation of peripheral microcirculation structures. NFC might be performed with different devices, such as a stereomicroscope, videocapillaroscope, dermatoscope, and ophthalmoscope, which exhibit different sensitivities and specificities. Stereomicroscopy magnifies images up to 50 times and provides detailed information regarding the microcirculation; assessment of the entire nailbed enables widefield NFC. Videocapillaroscopy allows the storage of images and uses magnification up to 600 times, thus enabling exact measurements of individual capillaries using specific softwares [38].

A study analyzed videocapillaroscopy with 200x magnification and stereomicroscopy (10 to $25 \mathrm{x}$ magnification) among patients with RP. Both techniques were similar in diagnostic performance and reproducibility regarding the evaluation of several capillaroscopic parameters (number of capillaries $/ \mathrm{mm}$, capillary dimension, and microhemorrhages) (B) [39]. In this study, the diagnostic accuracy to discriminate patients with SSc from healthy individuals was similar for both techniques (B) [39]. Similarly to the data described above, the two methods exhibited a good correlation for capillary density among patients with SSc (B) [40].

Dermatoscopy is widely used in dermatology to investigate skin lesions, but the images have less magnification and poorer resolution. A prospective study designed to analyze the diagnostic performance of dermatoscopy with 30x magnification among patients with RP found good 
concordance compared with conventional capillaroscopy, with a sensitivity and specificity of 76.9 and $90.9 \%$ for the "SD" pattern, respectively (B) [41]. Similar findings were reported by other authors, who described good diagnostic accuracy of dermatoscopy for connective tissue diseases (B) [42].

Some authors have suggested the use of portable devices, such as the ophthalmoscope (C) [43]. In an observational study that analyzed nailfold abnormalities among SSc patients with an ophthalmoscope or dermatoscope (with polarized light and without im mersion), Baron et al. found good reproducibility in the identification of dilated capillaries and giant capillaries. However, there was no concordance in the identification of avascular areas (B) [43].

\section{Recommendation 2}

Nailfold capillaroscopy is a complementary diagnostic method for evaluation of the microvascular structure. It might be performed with a stereomicroscope, videocapillaroscope, dermatoscope, or ophthalmoscope. The stereomicroscope and videocapillaroscope exhibit excellent reliability for the evaluation of capillaroscopic abnormalities, which suggests that any of them might be indistinctly used for assessment of peripheral microangiopathy among individuals with systemic sclerosis and Raynaud's phenomenon. The latter two (dermatoscope and ophthalmoscope) provide less magnified images of poorer quality. However, they might be used in services in which stereomicroscopy and videocapillaroscopy are not available. All these techniques are examiner-dependent, and they do not point, alone, to the diagnosis of disease.

\section{What morphological parameters should be evaluated in NAILFOLD CAPILLAROSCOPY?}

Only the morphological aspects of the distal row capillaries are evaluated using NFC. The capillaroscopic pattern is not established based on the evaluation of one single parameter but on a combination of numerical and morphological characteristics [44]. Table 3 describes the main morphological characteristics, which should be evaluated on NFC [44-46].

Table 3 Morphological parameters assessed on capillaroscopy

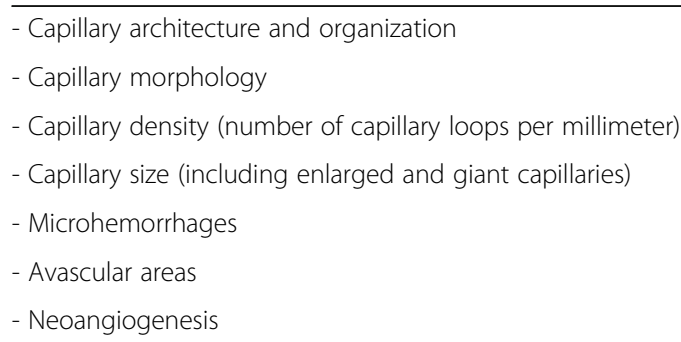

\section{Capillary architecture and organization}

Normally, the distal row of capillaries are orderly distributed in horizontal lines or palisade array on the periungueal region. This distribution is homogeneous and regular, and perpendicular to the nail edge (B) [44]. It is important to bear in mind that there are variations in NFC findings even among healthy individuals (B) $[44,45,47]$.

\section{Capillary morphology}

Individual loops look like hairpins (C) [48]. Normal capillaries have an inverted " $U$ " shape with a thinner arterial (afferent) side. Discrete abnormalities might be found in healthy individuals, such as tortuous or "meandering" loops (capillaries with limbs crossed upon themselves), branching, and few dilatation (D) $[49,50]$.

\section{Capillary density}

Is defined as the number of capillary loops per millimeter in each finger. It is one of the most significant parameters for the early identification of individuals at high risk for the development of autoimmune rheumatic diseases, especially the ones with RP (B) [44]. The average number of capillaries per millimeter is variable among studies, ranging from 7 to 12 capillaries/mm (B) $[44,45],(C)$ [51].

\section{Capillary size}

Several values and measurements are described in the literature relative to the capillary size. The most significant measurements that can be measured using videocapillaroscopy are the capillary width, diameter of the afferent (arterial) side, diameter of the efferent (venous) side, and diameter of the apical loop (B) [44, 53], (C) [52].

\section{Enlarged and giant capillaries}

According to Maricq et al., capillaries are considered to be dilated when all three loop sides-afferent, apical, and efferent-are 4 to 9 times larger than the normal diameters. Giant capillaries are extremely enlarged loops, with diameters 10 or more times larger than the normal adjacent loops (B) [54]. According to more recent classifications or software measurement of capillary size, giant capillaries are those with arterial, venous, or apical diameters over $50 \mu \mathrm{m}$ (B) [55], (C) [27], (D) [56]. Capillaries with a diameter greater than $20 \mu \mathrm{m}$ are defined as enlarged (B) [55].

\section{Microhemorrhages}

These are easily visible dark areas on the nailfold capillary bed, and they occur due to rupture of the capillary wall. Microhemorrhages might be focal or diffuse. Isolated microhemorrhages might occur in healthy individuals due to microtrauma [45]. In SSc and scleroderma 
spectrum disorders, microhemorrhages usually exhibit a diffuse distribution and are close to dilated capillaries, which tend to become broken more easily.

\section{Avascular areas}

Avascular areas may be variably defined and can be focal or diffuse. As a rule, they are defined based on the number of capillaries per millimeter; diffuse devascularization is present when the number of capillaries per millimeter is $\leq 7$. Alternatively, diffuse devascularization is defined as a distance larger than $500 \mu \mathrm{m}$ between two adjacent loops (D) [56]. Avascular areas are also defined as the absence of two or more successive capillaries. They are attended by tissue hypoxia and occur in SSc spectrum disorders, in which case they are highly relevant because they are associated with the severity of the disease (B) [57], (C) [58]. Some authors quantify the extension of devascularization by means of a semiquantitative scale ranging from 0 to 3 : 0 -absence of avascular areas; $1-$ discrete devascularization (one or two avascular areas); 2-moderate devascularization (more than two avascular areas); 3-extensive and confluent devascularization areas (D) $[56],(B)[39,45]$.

\section{Neoangiogenesis}

Branched capillaries with a highly heterogeneous shape, usually due to capillary neoformation (angiogenesis), may occur among individuals with secondary RP (D) [54].

\section{Recommendation 3}

Nailfold capillaroscopy is a noninvasive, relatively easy to perform, complementary method for assessment of the microcirculation, and it demands training from examiners. As a rule, the main parameters to be assessed are as follows: capillary architecture and morphology, capillary density (number of capillaries per millimeter) and size, presence of microhemorrhages, devascularization, and neoangiogenesis.

\section{What are the normal parameters on NAILFOLD CAPILLAROSCOPY?}

Among healthy individuals, loops are homogeneous in shape, exhibiting a homogeneous and regular array perpendicular to the nailbed (Fig. 1a). Discrete variations, such as tortuous and "meandering" loops and a visible subpapillary venous plexus, might occur, particularly among light-skinned individuals (B) [45]. Normal findings are described in Table 4.

\section{Recommendation 4}

Findings on normal nailfold capillaroscopy include a palisade array of capillaries, with a regular and homogeneous distribution, and the absence of devascularization areas. It is important to bear in mind the wide variability in morphology and size of the loops among healthy individuals, and even between the fingers of one and the same individual.

\section{Which morphological abnormalities are present in the "SD" pattern?}

The term "SD" (scleroderma) pattern, first described in 1980, alludes to a set of typical abnormalities on NFC found among patients with SSc (B) [26]. It is characterized by the presence of dilated and giant capillaries, a reduced capillary density, architectural distortion, morphological abnormalities in loops, microhemorrhages, and neoangiogenesis (Fig. 1b) [59, 60]. Structures might be blurred by edema, and anomalous connective tissue proliferation might occur [61]. In the early 2000's, capillaroscopic abnormalities were sequentially classified into three patterns based on the microcirculation involvement: "early" pattern, characterized by few dilated capillaries, small
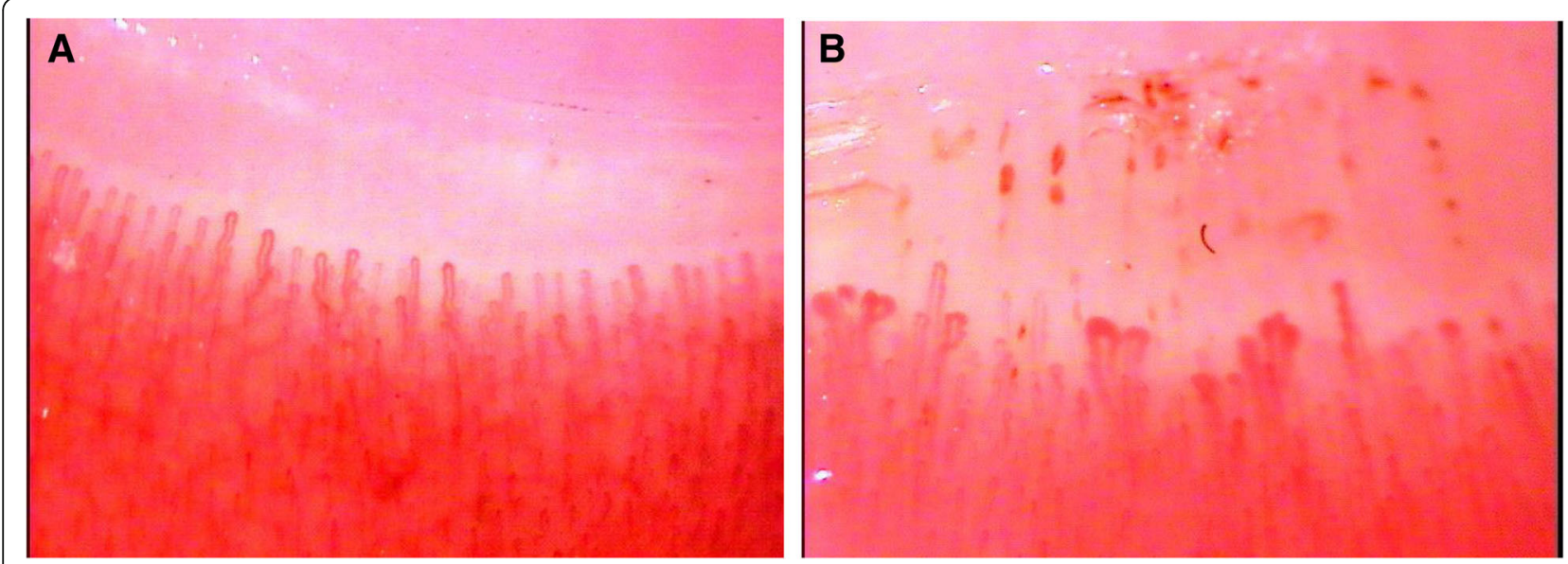

Fig. 1 Nailfold capillaroscopy showing a normal pattern (a) and a scleroderma pattern, characterized by the presence of enlarged and giant capillaries, reduced capillary density, and microhemorrhages (b) 
Table 4 Normal morphological parameters on capillaroscopy

\begin{tabular}{ll}
\hline Capillaroscopic parameters & Normal pattern \\
\hline Skin transparency and visibility & Capillaries are clearly visible \\
Pericapillary edema & Absent \\
Subpapillary venous plexus & Visible in > 30\% of healthy individuals \\
Capillary architecture & Capillaries perpendicular to the nail edge \\
Capillary morphology & Inverted "U" shape \\
Capillary loop diameter & $<20 \mu m$ \\
Tortuosity & Normally absent \\
Dilated and giant loops & Absent \\
Neoangiogenesis & Absent \\
Microhemorrhages & Normally absent \\
Capillary density & 7 to 12 capillaries/mm \\
Avascular areas & Absent \\
Capillary blood flow & Dynamic, without stasis \\
\hline Adapted from Chojns
\end{tabular}

Adapted from Chojnowski et al., $2016^{59}$ (D)

number of microhemorrhages, no evident capillary loss and relatively preserved distribution; "active" pattern, in which giant capillaries and microhemorrhages are frequent, and there is a discrete distortion of the capillary architecture; "late" pattern, with few or no giant capillaries, and the presence of neoangiogenesis and large avascular areas [24].

In addition to the aforementioned morphological abnormalities on NFC, the "SD" pattern includes histopathological and functional changes, such as endothelial edema, inflammatory infiltrates, and slower blood flow $[49,62]$.

\section{Recommendation 5}

The "SD" pattern on nailfold capillaroscopy exhibits dilated capillaries, a reduced density of the capillary loops, distortion of the capillary architecture, and microhemorr hages.

\section{Should CAPILLAROSCOPY be indicated to all individuals with RAYNAUD'S phenomenon?}

Under normal conditions, and also among individuals with primary RP, NFC exhibits regular capillary loops, some dilated capillaries eventually, and an absence of giant capillaries or avascular areas (C) [63]. Microcirculation abnormalities, such as increased capillary diameter, architectural disorganization, angiogenesis, and avascular areas, point to a possible connective tissue disease or secondary $\mathrm{RP}(\mathbf{B})[5,64]$.

In a study that analyzed microvascular abnormalities among individuals with undifferentiated connective tissue disease (UCTD), RP was found in $52.5 \%$ of the sample (B) [65]. The most frequent microvascular abnormalities were giant capillaries, and dilated and irregular capillaries. The patients with UCTD but without RP exhibited unspecific microcirculation changes (B) [65].
A retrospective study was conducted with 67 patients to analyze the sensitivity, specificity, positive (PPV), and negative (NPV) predictive value of capillaroscopy for the diagnosis of connective tissue diseases (B) [2]. The sensitivity and specificity for the diagnosis of SSc was 89.4 and $80 \%$, respectively, when the "SD" pattern was found on NFC. PPV and NPV for SSc was 68 and 94\%, respectively (B) [2]. The sensitivity and specificity of SLE-related capillaroscopic patterns was 33 and $95.4 \%$, respectively, with PPV of $71.4 \%$ and NPV of $80.7 \%$. The sensitivity and specificity for diagnosis of dermatomyositis/polymyositis was 60 and 96.3\%, respectively, with PPV $60 \%$ and NPV 96.3\%. The sensitivity and specificity for diagnosis of MCTD was 20 and 100\%, respectively, with PPV of $100 \%$ and NPV 93.1\% (B) [2].

A prospective study performed to analyze the prognostic value of the "SD" pattern on NFC among individuals with primary RP $(n=3029)$ found that $37 \%$ of the sample developed some connective tissue disease (SSc, SLE, rheumatoid arthritis, Sjögren's syndrome, MCTD, dermatomyositis, polymyositis). The sensitivity, specificity, PPV, and NPV of the "SD" pattern in regard to SSc was 94, 92, 52, and 99\%, respectively (B) [66].

Corroborating these findings, another prospective study investigated the contribution of NFC to the assessment of the progression of individuals with RP. The sample included 288 patients with primary RP, $11.8 \%$ of whom exhibited a transition from isolated RP to SSc, and 42 patients to other connective tissue diseases (B) [67].

Additionally, other authors reported that microcirculation abnormalities, such as avascular areas, giant capillaries, and distortion of the capillary architecture, were capillaroscopic predictors of connective tissue diseases among individuals with RP (B) [13]. 
It should be observed that normal NFC findings are diagnostic criteria for primary RP, as formulated by LeRoy et al. in 1992 (B) [68], and they are also included in the new diagnostic criteria suggested by Maverakis et al. in 2014 (B) [69].

\section{Recommendation 6}

Nailfold capillaroscopy is highly relevant for the differential diagnosis of connective tissue diseases among individuals with Raynaud's phenomenon. Among them, NFC exhibits considerable predictive value regarding the development of autoimmune rheumatic disease and, thus, it should be performed in all individuals with Raynaud's phenomenon.

\section{What is the relevance of CAPILLAROSCOPY for the early} diagnosis of systemic sclerosis?

Several studies have confirmed the relevance of NFC for the early diagnosis of SSc. This method was recently included in the classification criteria for SSc proposed by the American College of Rheumatology (ACR) and European League Against Rheumatism (EULAR), despite the lack of consensus on the technique to be used and the variables that should be analyzed (D) [70, 71]. Preliminary criteria for very early diagnosis of systemic sclerosis (VE DOSS) were also published. According to the latter, the main clinical characteristics of very early SSc are RP, positive autoantibodies (anticentromere and antitopoisomerase), and "SD" pattern on NFC (D) [72]. These parameters allow the identification of SSc patients in a very early stage of disease, allowing early treatment and represent a true "window of opportunity."

A study that analyzed morphological and functional microcirculation abnormalities among patients diagnosed with SSc found that in the early stages of disease, both widefield NFC and videocapillaroscopy allowed the detection of milder abnormalities, such as a higher capillary density, smaller number of giant capillaries, and smaller avascular areas, by comparison to patients with established disease (B) [73].

Prospective studies that assessed NFC performance in SSc demonstrated the pathophysiological sequence of microvascular damage (B) $[28,74]$.

\section{Recommendation 7}

Although there is no medication able to hinder the natural progression of disease, recent advances were made in the treatment of systemic sclerosis based on new drugs with effects on vascular remodeling, such as endothelin receptor antagonists, phosphodiesterase inhibitors, and prostanoids. Therefore, optimization of diagnosis in early stages of disease, including identification of milder structural abnormalities, might provide an opportunity to prevent the progression of systemic sclerosis. Within this context, nailfold capillaroscopy is useful for the early diagnosis of disease.

\section{Is the "SD" pattern specific for systemic sclerosis? Do} other diseases exhibit this pattern?

Present in approximately 80 to $90 \%$ of SSc cases, the "SD" pattern can, however, also be found among patients with other autoimmune rheumatic diseases, such as dermatomyositis and MCTD (C) [26], (D) [75]. A study analyzed the predictive value of the "SD" pattern for the diagnosis of SSc in a cohort of unselected patients. The results showed a sensitivity, specificity, PPV, and NPV of 71, 95, 84 , and $90 \%$, respectively (B) [76].

A prospective observational study with more than 3000 patients and 5.3-year follow-up found that the "SD" pattern on NFC was significantly associated with SSc. The "SD" pattern was detected in $94 \%$ of the patients who developed SSc six months before onset of disease manifestations (B) [66]. A total of $71 \%$ of the patients who developed dermatomyositis and $37 \%$ of the those who progressed to MCTD exhibited the "SD" pattern (B) [66].

In a series of patients with connective tissue disease and RP, $87.5 \%(n=14)$ of the 16 participants with diffuse cutaneous SSc, and $61.6 \%(n=53)$ of the 86 patients with limited cutaneous SSc, exhibited the "SD" pattern. Additio nally, $13.8 \%$ of the patients with UCTD, $8.5 \%$ of those with SLE, and $26.9 \%$ of the ones with dermatomyositis and polymyositis exhibited the capillaroscopic pattern associated with SSc. In turn, none of the patients with rheumatoid arthritis (RA) or Sjögren's syndrome exhibited this pattern (B) [4]. When the "SD" pattern is found in these other diseases, it should always raise suspicion of SSc overlap syndrome.

\section{Recommendation 8}

Identification of the "SD" pattern on nailfold capillaroscopy is suggestive of systemic sclerosis. This pattern is also found in other connective tissue diseases, such as dermatomyositis and mixed connective tissue disease, and less frequently in systemic lupus erythematosus and undifferentiated connective tissue disease.

What CAPILLAROSCOPIC abnormalities are found in other autoimmune rheumatic diseases (systemic lupus erythematosus, rheumatoid arthritis, antiphospholipid syndrome, systemic vasculitis)? Systemic lupus erythematosus

SLE is a multisystem, chronic inflammatory autoimmune disease that might be accompanied by microvascular damage. The findings on NFC have poor specificity for early diagnosis and prognostic assessment, as no specific pattern has been identified for this disease (B) [77, 78]. The main abnormal findings are increased capillary tortuosity, which occurs in more than $40 \%$ of patients, and an 
increased capillary length. Smaller proportions of patients might exhibit focal areas of capillary loss and increased visibility of the subpapillary venous plexus (B) [27, 78], (C) [79].

A retrospective analysis of 123 individuals diagnosed with SLE subjected to NFC found that the "major" capillary abnormalities (elongated loops, dilatation of the efferent side, increased tortuosity, and branching) occurred in $35.8 \%$ of the sample (B) [77]. A total of $28.5 \%$ of the patients exhibited a normal pattern on NFC, and 33.3\% showed "minor" abnormalities (B) [77].

In another study with SLE patients, NFC findings such as increased capillary tortuosity, avascular areas and microhemorrhages, were more common among the cases with RP compared to those without it (B) [35].

\section{Rheumatoid arthritis}

The data on capillaroscopic findings among RA patients are scarce in the literature. In 1970, Redisch et al. reported that the most frequent findings in a series of RA patients were an increased capillary tortuosity, an increased capillary length, and a prominent subpapillary venous plexus (C) [80]. Another study of 32 RA patients reported capillary tortuosity and prominent subpapillary venous plexus, especially among the cases with positive antinuclear antibodies (C) [81]. In one study of 62 RA patients, the most frequent finding was a prominent subpapillary venous plexus, which was present in $69 \%$ of cases, and an increased capillary length (58\%) (C) [82].

\section{Antiphospholipid syndrome}

Patients with antiphospholipid syndrome (APS) exhibit symmetric microhemorrhages (B) [83]. Morphological abnormalities are found in primary and secondary APS; the variation in the loop length is considerably more frequent in primary APS, while microhemorrhages are more evident in cases of APS secondary to SLE (B) [84].

\section{Systemic vasculitis}

A study which analyzed capillaroscopic abnormalities among patients with vasculitis (polyarteritis nodosa, Churg-Strauss syndrome, hypersensitivity vasculitis, and temporal arteritis) found discrete and isolated changes in $73 \%$ of the sample. Microhemorrhage was the most frequent finding among cases with active disease (C) [85]. Overall, the capillaroscopic findings were few and non-specific.

\section{Behçet's disease}

Some authors analyzed NFC findings of 128 patients with Behçet's disease. Discrete abnormalities were found in $40 \%$ of the sample, an increased capillary diameter in $26 \%$, microhemorrhages in $16 \%$, and capillary loss in $2 \%$ (B) [86].

\section{Sjögren's syndrome}

NFC was normal in more than half of patients diagnosed with Sjögren's syndrome without RP (C) [87]. Non-specific abnormalities, such as tortuous and irregular capillaries and increased visibility of the subpapillary venous plexus, were described in $29.5 \%$ of 61 individuals with primary Sjögren's syndrome (B) [88].

\section{Recommendation 9}

Overall, the capillaroscopic abnormalities found in other autoimmune rheumatic diseases, such as systemic lupus erythematosus, rheumatoid arthritis, antiphospholipid syndrome and systemic vasculitis, are non-specific.

\section{Should NAILFOLD CAPILLAROSCOPY be repeated during the follow-up of patients with systemic sclerosis?}

Several studies have consistently shown that devascularization and distortion of the capillary architecture-which characterize late microvascular injury among patients with $\mathrm{SSc}$-are strong predictors of complications involving target organs, such as the skin, lungs, heart, gastrointestinal tract, and kidneys (B) [28, 89-91], (C) [92], (D) [93].

Some studies have reported results after treatment of SSc patients, including parameters such as blood flow, capillary permeability, and loop morphology. Thus, NFC might play a role in the monitoring of treatment (B) [94, 95]. However, this indication is still controversial, and studies with larger samples and longer durations of follow-up are needed.

\section{Recommendation 10}

Nailfold capillaroscopy plays a relevant role in the diagnosis of systemic sclerosis, as microvascular damage is an early marker of disease. It is also useful to assess the severity of disease. However, there is still no consensus on its role in the follow-up of SSc patients.

\section{Are CAPILLAROSCOPY abnormalities associated with the risk of development of digital ulcers in patients with systemic sclerosis?}

Digital ulcers (DU) are a common complication, affecting 30 to $50 \%$ of SSc patients $[96,97]$. Although the understanding of the pathophysiology of DU has improved in recent years, the identification of patients at high risk of developing DU still poses a challenge. Some studies have described endothelial dysfunction biomarkers, and NFC findings as potential predictors of new DU (B) [98]. Avascular areas found on NFC might be related to an imbalance of angiogenic factors, and a higher risk of DU $[99,100]$.

A study that analyzed patients with SSc and RP found that individuals with DU predominantly exhibited the late pattern on NFC (neoangiogenesis, large avascular areas, and few dilated or giant capillaries) compared with those without DU. Among this latter group of patients, 
the capillaroscopic abnormalities corresponded to the active pattern (giant capillaries, microhemorrhages, and discrete avascular areas) (B) [89]. Corroborating these findings, a prospective observational study with 77 SSc patients found, on videocapillaroscopy with 200x magnification, that the development of DU during the 3-year follow-up was associated with the late pattern on NFC, particularly capillary disorganization, microhemorrhages, and avascular areas (B) [90]. Logistic regression analysis showed that this capillaroscopic pattern was the best independent predictor of both the first episode and recurrence of DU in the analyzed population (B) [90]. Reinforcing these findings, a study with 103 SSc patients subjected to videocapillaroscopy also reported a strong association between the late pattern abnormalities and DU (B) [28]. On the other side, an observational study with 36 SSc patients designed to investigate capillaroscopic patterns and their association with DU found the active "SD" pattern in all the patients with DU, but only in $47 \%$ of those without DU (C) [101].

Some authors have suggested quantitative risk scores for prognostic purposes of DU development (A) [102], (B) [103]. One score, the Capillaroscopic Skin Ulcer Risk Index (CSURI) is calculated by means of the equation $D_{x} M / N^{2}$, in which $D$ is the maximum diameter of giant capillaries, $\mathrm{M}$ the number of giant capillaries, and $\mathrm{N}$ the number of capillaries in the distal row (B) [103-105]. In a multicenter study, CSURI exhibited 92.9 and $81.4 \%$ sensitivity and specificity, respectively, for the development of DU within three months of videocapillaroscopy, with an area under the receiver operating characteristic (ROC) curve of 0.884 (B) [104]. A limitation of this score is the mandatory presence of giant capillaries, which excludes the abnormalities corresponding to the late pattern.

\section{Recommendation 11}

In patients with systemic sclerosis microvascular abnormalities are frequently observed on capillaroscopy. Structural abnormalities, such as devascularization areas and distortion of the capillary bed architecture, characteristic of the late microvascular damage, are strong predictors of the occurrence of digital ulcers in this population of patients.

Is there a correlation between CAPILLAROSCOPIC findings and severity and prognosis among patients with systemic sclerosis?

Several studies have shown a positive correlation between the degree and extension of microvascular damage on NFC and the involvement of internal organs in SSc (B) [106-109].

The preliminary attempts to establish a correlation between NFC findings and clinical abnormalities among patients with SSc were initiated in the 1970s with the study by Maricq et al. (C) [54]. In that study, with patients with SSc $(n=28)$ and dermatomyositis $(n=3)$, a positive correlation was found between the degree and extension of microvascular damage and involvement of many body systems (C) [54]. Although criticized by its small sample size, the results of the study suggest that the number of involved organs is associated with more severe capillaroscopic abnormalities. Another observational study conducted with patients with isolated RP and SSc analyzed the association between antinuclear antibodies, capillaroscopic patterns, and clinical findings. The results showed that patients with SSc and the "active" capillaroscopic pattern exhibited the highest levels of target-organ involvement, including the kidneys, muscles, and skin in particular (C) [30]. These patients were also at higher risk of developing hypertension and anemia. In turn, the individuals with the "slow" capillaroscopic pattern, i.e., with a predominance of dilated loops and few avascular areas, exhibited a lower frequency of visceral involvement (C) [30]. Corroborating the aforementioned findings, an observational study with 112 patients, 45 of whom had SSc, found that more severe abnormalities on NFC were associated with more extensive systemic involvement (C) [109].

A prospective observational study that independently analyzed two cohorts of SSc patients found that organ involvement was strongly associated with the pattern on NFC (B) [110]. However, conflicting results have also been reported, as some authors did not find a correlation between the systemic involvement and abnormalities on NFC (B) [111].

In a study conducted in Spain, progressive capillary loss on NFC was associated with greater disease severity and an increased risk of DU occurrence (B) [112]. A study performed in 2007 found that patients with the "late" capillaroscopic pattern (on nailfold videocapillaroscopy) were at higher risk of disease activity $(\mathrm{OR}=3.50$, 95\% CI: 1.31 to 9.39$)$ and DU occurrence (OR $=5.74$, 95\% CI: 2.08 to 15.89 ) (B) [28].

Other studies have shown that among patients with SSc, the degree of capillary loss on NFC differs between those with or without pulmonary hypertension (B) [106, 107]. A study found that SSc patients with severe capillaroscopic abnormalities exhibited a higher prevalence of ground-glass opacities on high-resolution computed tomography (B) [29]. Finally, a study conducted with SSc patients reported that the risk of death was higher among those with higher degrees of devascularization on NFC (B) [113]. Therefore, NFC might be used for the assessment of disease severity and to predict the occurrence of systemic complications among patients with SSc.

\section{Recommendation 12}

Nailfold capillaroscopy plays a relevant role in the diagnosis of systemic sclerosis. Despite being controversial, 
the available evidence indicates a positive correlation between capillaroscopic abnormalities and the involvement of target organs.

\section{Conclusions}

Nailfold capillaroscopy is increasingly being used among rheumatologists. It is an important method for the investigation of RP and for the early diagnosis of SSc. In the present recommendations, the main indications, the technical equipments that should be used, and standardization on nomenclature, parameters, and the interpretation of NFC findings were proposed based on a systematic review of the literature and the experience of a panel of experts. Thus, the standardized indications and definitions will increase the reliability and quality of NFC performance among rheumatologists and clinicians.

\section{Additional file}

Additional file 1: Methodological details, expanded results and rationale of the formulated questions for the present recommendations [114-117]. (DOCX 35 kb)

\section{Abbreviations \\ APS: Antiphospholipid syndrome; DU: Digital ulcers; MCTD: Mixed connective tissue disease; NFC: Nailfold capillaroscopy; NPV: Negative predictive value; PPV: Positive predictive value; RA: Rheumatoid arthritis; RP: Raynaud's phenomenon; SD: Scleroderma; SLE: Systemic lupus erythematosus; SSC: Systemic sclerosis; UCTD: Undifferentiated connective tissue disease}

\section{Acknowledgements}

The authors wish to acknowledge the researchers Ricardo Simoes, Renata Buzzini, Wanderley Marques Bernardo, from the Brazilian Medical Association (Associação Médica Brasileira), Guidelines Project, who performed the systematic review that is presented in detail in the Additional file 1, funded by the Brazilian Society of Rheumatology.

\section{Funding}

Brazilian Society of Rheumatology. The funding body had no role in the design of the study and collection, analysis, and interpretation of data and in writing the manuscript.

\section{Authors' contributions}

All authors contributed to write and review the manuscript. All authors read and approved the final version of the manuscript.

\section{Competing interest}

Cristiane Kayser has received speaking fees from Bristol-Myers-Squibb. Eutilia Freire consultants for Janssen, has received personal or institutional support from Pfizer, Roche and Abbvie.

Markus Bredemeier, Maria Teresa Caleiro, Karina Capobianco, Tatiana Melo Fernandes, Lilian Lonzetti, Renata Miossi, Sheila M. A. Fontenele and Juliana Sekiyama declare that they have no competing interests.

Carolina de Souza Müller has received supporting for meetings and scientific events from Actelion, Pfizer, Abbvie, Janssen, Novartis, Roche.

\section{Ethics approval and consent to participate}

Not applicable.

\section{Publisher's Note}

Springer Nature remains neutral with regard to jurisdictional claims in published maps and institutional affiliations.

\section{Author details}

${ }^{1}$ Rheumatology Division, Escola Paulista de Medicina, Universidade Federal de São Paulo (UNIFESP), Rua Botucatu 740, $3^{\circ}$ andar, São Paulo, SP 04023-062, Brazil. ²Reumatology Service, Hospital Nossa Senhora da Conceição, Grupo Hospitalar Conceição, Porto Alegre, RS, Brazil. ${ }^{3}$ Rheumatology Division, Hospital das Clinicas HCFMUSP, Faculdade de Medicina, Universidade de Sao Paulo, Sao Paulo, Brazil. ${ }^{4}$ Rheumatology Service, Moinhos de Vento Hospital, Porto Alegre, Brazil. ${ }^{5}$ Rheumatology Division, Universidade Federal do Rio de Janeiro, Rio de Janeiro, Brazil. ${ }^{6}$ Departament of Medicine, Universidade Estadual do Ceará, Fortaleza, Brazil. ${ }^{7}$ Rheumatology Service, Universidade Federal da Paraíba, João Pessoa, Brazil. ${ }^{8}$ Rheumatology Service, Complexo Hospitalar da Santa Casa de Misericórdia de Porto Alegre, Universidade Federal de Ciências da Saúde de Porto Alegre, Porto Alegre, Brazil. ${ }^{9}$ Faculdade de Ciências Médicas, Universidade Estadual de Campinas (UNICAMP), Campinas, SP, Brazil. ${ }^{10}$ Rheumatology Division, Hospital de Clínicas, Universidade Federal do Paraná (UFPR), Curitiba, Brazil.

Received: 5 October 2018 Accepted: 20 December 2018

Published online: 22 January 2019

\section{References}

1. Cortes S, Cutolo M. Capillarosecopic patterns in rheumatic diseases. Acta Reumatol Port. 2007:32(1):29-36.

2. Wu PC, Huang MN, Kuo YM, Hsieh SC, Yu CL. Clinical applicability of quantitative nailfold capillaroscopy in differential diagnosis of connective tissue diseases with Raynaud's phenomenon. J Formos Med Assoc. 2013; 112(8):482-8.

3. Damjanov N, Pavlov-Dolijanović S, Zlatanović M. Capillaroscopy as a prognostic tool for the development of connective tissue disease in patients with Raynaud's phenomenon. Reumatizam. 2010;57(2):119-20.

4. Nagy Z, Czirják L. Nailfold digital capillaroscopy in 447 patients with connective tissue disease and Raynaud's disease. J Eur Acad Dermatol Venereol. 2004;18(1):62-8.

5. Mannarino E, Pasqualini L, Fedeli F, Scricciolo V, Innocente S. Nailfold capillaroscopy in the screening and diagnosis of Raynaud's phenomenon. Angiology. 1994;45(1):37-42.

6. Smith V, Beeckman S, Herrick AL, Decuman S, Deschepper E, De Keyser F, et al. An EULAR study group pilot study on reliability of simple capillaroscopic definitions to describe capillary morphology in rheumatic diseases. Rheumatology (Oxford). 2016;55(5):883-90.

7. Maricq HR, Carpentier PH, Weinrich MC, Keil JE, Franco A, Drouet P, Ponçot OC, Maines MV. Geographic variation in the prevalence of Raynaud's phenomenon: Charleston, SC, USA, vs Tarentaise, Savoie, France. J Rheumatol. 1993:20(1):706.

8. Linnemann B, Erbe M. Raynaud's phenomenon - assessment and differential diagnoses. Vasa. 2015;44(3):166-77.

9. Maricq HR, Carpentier PH, Weinrich MC, Keil JE, Palesch Y, Biro C, VionnetFuasset M, Jiguet M, Valter I. Geographic variation in the prevalence of Raynaud's phenomenon: a 5 region comparison. J Rheumatol. 1997;24(5): 879-89.

10. De Angelis R, Salaffi F, Grassi W. Raynaud's phenomenon: prevalence in an Italian population sample. Clin Rheumatol. 2006;25(4):506-10.

11. Block JA, Sequeira W. Raynaud's phenomenon. Lancet. 2001;357(9273):2042-8.

12. Cutolo M, Grassi W, Matucci CM. Raynaud's phenomenon and the role of capillaroscopy. Arthritis Rheum. 2003:48(11):3023-30.

13. Meli M, Gitzelmann G, Koppensteiner R, Amann-Vesti BR. Predictive value of nailfold capillaroscopy in patients with Raynaud's phenomenon. Clin Rheumatol. 2006;25(2):153-8.

14. Koenig M, Joyal F, Fritzler MJ, Roussin A, Abrahamowicz M, Boire G, et al. Autoantibodies and microvascular damage are independent predictive factors for the progression of Raynaud's phenomenon to systemic sclerosis: a twenty-year prospective study of 586 patients, with validation of proposed criteria for early systemic sclerosis. Arthritis Rheum. 2008;58(12): 3902-12.

15. Luggen M, Belhorn L, Evans T, Fitzgerald O, Spencer-Green G. The evolution of Raynaud's phenomenon: a longterm prospective study. J Rheumatol. 1995;22(12):2226-32.

16. Hirschl M, Hirschl K, Lenz M, Katzenschlager R, Hutter HP, Kundi M. Transition from primary Raynaud's phenomenon to secondary Raynaud's phenomenon identified by diagnosis of an associated disease: results of ten years of prospective surveillance. Arthritis Rheum. 2006;54(6):1974-81. 
17. Spencer-Green G. Outcomes in primary Raynaud phenomenon: a metaanalysis of the frequency, rates, and predictors of transition to secondary diseases. Arch Intern Med. 1998;158(6):595-600.

18. Kim SH, Kim HO, Jeong YG, Lee SY, Yoo WH, Choi TH, Lee SI. The diagnostic accuracy of power Doppler ultrasonography for differentiating secondary from primary Raynaud's phenomenon in undifferentiated connective tissue disease. Clin Rheumatol. 2008;27(6):783-6.

19. Ingegnoli F, Boracchi P, Gualtierotti R, Lubatti C, Meani L, Zahalkova L, et al. Prognostic model based on nailfold capillaroscopy for identifying Raynaud's phenomenon patients at high risk for the development of a scleroderma spectrum disorder: PRINCE (prognostic index for nailfold capillaroscopic examination). Arthritis Rheum. 2008;58(7):2174-82.

20. Guiducci S, Giacomelli R, Cerinic MM. Vascular complications of scleroderma. Autoimmun Rev. 2007;6(8):520-3.

21. Bussone $G$, Mouthon L. Interstitial lung disease in systemic sclerosis. Autoimmun Rev. 2011;10(5):248-55.

22. Tiev KP, Cabane J. Digestive tract involvement in systemic sclerosis. Autoimmun Rev. 2011;11(1):68-73.

23. Valentini G, Vettori S, Cuomo G, Iudici M, D'Abrosca V, Capocotta D, Del Gênio G, Santoriello C, Cozzolino D. Early systemic sclerosis: short-term disease evolution and factors predicting the development of new manifestations of organ involvement. Arthritis Res Ther. 2012;14(4):R188.

24. Cutolo M, Sulli A, Pizzorni C, Accardo S. Nailfold videocapillaroscopy assessment of microvascular damage in systemic sclerosis. J Rheumatol. 2000;27(1):155-60.

25. Grassi W, Medico PD, Izzo F, Cervini C. Microvascular involvement in systemic sclerosis: capillaroscopic findings. Semin Arthritis Rheum. 2001; 30(6):397-402.

26. Maricq HR, LeRoy EC, D'Angelo WA, Medsger TA Jr, Rodnan GP, Sharp GC, Wolfe JF. Diagnostic potential of in vivo capillary microscopy in scleroderma and related disorders. Arthritis Rheum. 1980;23(2):183-9.

27. Kabasakal Y, Elvins DM, Ring EF, McHugh NJ. Quantitative nailfold capillaroscopy findings in a population with connective tissue disease and in normal healthy controls. Ann Rheum Dis. 1996;55(8):507-12.

28. Caramaschi P, Canestrini S, Martinelli N, Volpe A, Pieropan S, Ferrari M, et al. Scleroderma patients nailfold videocapillaroscopic patterns are associated with disease subset and disease severity. Rheumatology (Oxford). 2007; 46(10):1566-9.

29. Bredemeier M, Xavier RM, Capobianco KG, Restelli VG, Rohde LE, Pinotti AF, et al. Nailfold capillary microscopy can suggest pulmonary disease activity in systemic sclerosis. J Rheumatol. 2004;31(2):286-94.

30. Chen ZY, Silver RM, Ainsworth SK, Dobson RL, Rust P, Maricq HR. Association between fluorescent antinuclear antibodies, capillary patterns, and clinical features in scleroderma spectrum disorders. Am Med. 1984;77(5):812-22.

31. Leteurtre E, Hachulla E, Janin A, Hatron PY, Brouillard M, Devulder B. Vascular manifestations of dermatomyositis and polymyositis. Clinical, capillaroscopic and histological aspects. Rev Med Interne. 1994;15(12):800-7.

32. Manfredi A, Sebastiani M, Cassone G, Pipitone N, Giuggioli D, Colaci M, et al. Nailfold capillaroscopic changes in dermatomyositis and polymyositis. Clin Rheumatol. 2015;34(2):279-84.

33. Mugii N, Hasegawa M, Matsushita T, Hamaguchi Y, Horie S, Yahata T, et al. Association between nail-fold capillary findings and disease activity in dermatomyositis. Rheumatology (Oxford). 2011;50(6):1091-8.

34. Groen H, ter Borg EJ, Postma DS, Wouda AA, van der Mark TW, Kallenberg CG. Pulmonary function in systemic lupus erythematosus is related to distinct clinical, serologic, and nailfold capillary patterns. Am J Med. 1992; 93(6):619-27.

35. Pavlov-Dolijanovic S, Damjanov NS, Vujasinovic Stupar NZ, Marcetic DR, Sefik-Bukilica MN, Petrovic RR. Is there a difference in systemic lupus erythematosus with and without Raynaud's phenomenon? Rheumatol Int 2013:33(4):859-65.

36. de Holanda Mafaldo Diógenes A, Bonfá E, Fuller R, Correia Caleiro MT. Capillaroscopy is a dynamic process in mixed connective tissue disease. Lupus. 2007;16(4):254-8.

37. Granier F, Vayssairat M, Priollet $P$, Housset E. Nailfold capillary microscopy in mixed connective tissue disease. Comparison with systemic sclerosis and systemic lupus erythematosus. Arthritis Rheum. 1986;29(2):189-95.

38. Ingegnoli F, Gualtierotti R, Lubatti C, Zahalkova L, Meani L, Boracchi P, et al. Feasibility of different capillaroscopic measures for identifying nailfold microvascular alterations. Semin Arthritis Rheum. 2009;38(4):289-95.
39. Sekiyama JY, Camargo CZ, Eduardo L, Andrade C, Kayser C. Reliability of widefield nailfold capillaroscopy and video capillaroscopy in the assessment of patients with Raynaud's phenomenon. Arthritis Care Res (Hoboken). 2013, 65(11):1853-61.

40. Wildt M, Wuttge DM, Hesselstrand R, Scheja A. Assessment of capillary density in systemic sclerosis with three different capillaroscopic methods. Clin Exp Rheumatol. 2012;30(2 Suppl 71):S50-4.

41. Beltrán E, Toll A, Pros A, Carbonell J, Pujol RM. Assessment of nailfold capillaroscopy by $\times 30$ digital epiluminescence (dermoscopy) in patients with Raynaud phenomenon. Br J Dermatol. 2007;156(5):892-8.

42. Bergman R, Sharony L, Schapira D, Nahir MA, Balbir-Gurman A. The handheld dermatoscope as a nail-fold capillaroscopic instrument. Arch Dermatol. 2003;139(8):1027-30

43. Baron M, Bell M, Bookman A, Buchignani M, Dunne J, Hudson M, et al. Office capillaroscopy in systemic sclerosis. Clin Rheumatol. 2007;26(8):1268-74.

44. Ingegnoli F, Gualtierotti R, Lubatti C, Bertolazzi C, Gutierrez M, Boracchi P, et al. Nailfold capillary patterns in healthy subjects: a real issue in capillaroscopy. Microvasc Res. 2013;90:90-5.

45. Andrade LE, Gabriel Júnior A, Assad RL, Ferrari AJ, Atra E. Panoramic nailfold capillaroscopy: a new reading method and normal range. Semin Arthritis Rheum. 1990;20(1):21-31.

46. Boulon C, Devos S, Mangin M, et al. Reproducibility of capillaroscopic classifications of systemic sclerosis: results from the SCLEROCAP study. Rheumatology (Oxford). 2017;56(10):1713-20.

47. Piotto DP, Sekiyama J, Kayser C, Yamada M, Len CA, Terreri MT. Nailfold videocapillaroscopy in healthy children and adolescents: description of normal patterns. Clin Exp Rheumatol. 2016;34(Suppl 100(5)):193-9.

48. Herrick AL, Moore T, Hollis S, Jayson MI. The influence of age on nailfold capillary dimensions in childhood. J Rheumatol. 2000;27(3):797-800.

49. Marica HR, Maize JC. Nailfold capillary abnormalities. Clin Rheum Dis. 1982; $8(2): 455-78$

50. Jones BF, Oral M, Morris CW, Ring EF. A proposed taxonomy for nailfold capillaries based on their morphology. IEEE Trans Med Imaging. 2001;20(4):33341.

51. Hoerth C, Kundi M, Katzenschlager R, Hirschl M. Qualitative and quantitative assessment of nailfold capillaries by capillaroscopy in healthy volunteers. Vasa. 2012:41(1):19-26.

52. Lo LC, Lin KC, Hsu YN, Chen TP, Chiang JY, Chen YF, et al. Pseudo threedimensional vision-based nail-fold morphological and hemodynamic analysis. Comput Biol Med. 2012;42(9):873-84.

53. Anderson ME, Allen PD, Moore T, Hillier V, Taylor CJ, Herrick AL Computerized nailfold video capillaroscopy -- a new tool for assessment of Raynaud's phenomenon. J Rheumatol. 2005;32(5):841-8.

54. Maricq HR, Spencer-Green G, LeRoy EC. Skin capillary abnormalities as indicators of organ involvement in scleroderma (systemic sclerosis), Raynaud's syndrome and dermatomyositis. Am J Med. 1976;61(6):862-70.

55. Sulli A, Secchi ME, Pizzorni C, Cutolo M. Scoring the nailfold microvascular changes during the capillaroscopic analysis in systemic sclerosis patients. Ann Rheum Dis. 2008;67:885-7

56. Etehad Tavakol M, Fatemi A, Karbalaie A, Emrani Z, Erlandsson BE. Nailfold Capillaroscopy in rheumatic diseases: which parameters should be evaluated? Biomed Res Int. 2015;2015:974530.

57. Zufferey P, Depairon M, Chamot AM, Monti M. Prognostic significance of nailfold capillary microscopy in patients with Raynaud's phenomenon and scleroderma-pattern abnormalities. A six-year follow-up study. Clin Rheumatol. 1992;11(4):536-41.

58. Cutolo M, Pizzorni C, Sulli A. Nailfold video-capillaroscopy in systemic sclerosis. Z Rheumatol. 2004;63(6):457-62.

59. Chojnowski MM, Felis-Giemza A, Olesińska M. Capillaroscopy - a role in modern rheumatology. Reumatologia. 2016;54(2):67-72.

60. Carpentier PH, Maricq HR. Microvasculature in systemic sclerosis. Rheum Dis Clin N Am. 1990;16(1):75-91.

61. Bollinger $A$, Jäger $K$, Siegenthaler W. Microangiopathy of progressive systemic sclerosis. Evaluation by dynamic fluorescence videomicroscopy. Arch Intern Med. 1986;146(8):1541-5.

62. Thompson RP, Harper FE, Maize JC, Ainsworth SK, LeRoy EC, Maricq HR. Nailfold biopsy in scleroderma and related disorders. Correlation of histologic, capillaroscopic, and clinical data. Arthritis Rheum. 1984;27(1):97-103.

63. Houtman PM, Kallenberg CG, Fidler V, Wouda AA. Diagnostic significance of nailfold capillary patterns in patients with Raynaud's phenomenon. An analysis of patterns discriminating patients with and without connective tissue disease. J Rheumatol. 1986;13(3):556-63. 
64. Le JH, Cho Kl. Association between endothelial function and microvascular changes in patients with secondary Raynaud's phenomenon. Clin Rheumatol. 2014;33(11):1627-33.

65. De Angelis R, Cerioni A, Del Medico P, Blasetti P. Raynaud's phenomenon in undifferentiated connective tissue disease (UCTD). Clin Rheumatol. 2005; 24(2):145-51.

66. Pavlov-Dolijanovic S, Damjanov NS, Stojanovic RM, Vujasinovic Stupar NZ, Stanisavljevic DM. Scleroderma pattern of nailfold capillary changes as predictive value for the development of a connective tissue disease: a follow-up study of 3,029 patients with primary Raynaud's phenomenon. Rheumatol Int. 2012;32(10):303945.

67. Ingegnoli F, Boracchi P, Gualtierotti R, Biganzoli EM, Zeni S, Lubatti C, Fantini F. Improving outcome prediction of systemic sclerosis from isolated Raynaud's phenomenon: role of autoantibodies and nail-fold capillaroscopy. Rheumatology (Oxford). 2010;49(4):797-805.

68. LeRoy EC, Medsger TA Jr. Raynaud's phenomenon: a proposal for classification. Clin Exp Rheumatol. 1992;10(5):485-8.

69. Maverakis E, Patel F, Kronenberg DG, Chung L, Fiorentino D, Allanore Y, et al. International consensus criteria for the diagnosis of Raynaud's phenomenon. J Autoimmun. 2014;48-49:60-5.

70. van den Hoogen F, Khanna D, Fransen J, Johnson SR, Baron M, Tyndall A, et al. 2013 classification criteria for systemic sclerosis: an American College of Rheumatology/European league against rheumatism collaborative initiative. Arthritis Rheum. 2013;65(11):2737-47.

71. Valentini G, Marcoccia A, Cuomo G, ludici M, Vettori S. The concept of early systemic sclerosis following 2013 ACR\EULAR criteria for the classification of systemic sclerosis. Curr Rheumatol Rev. 2014;10(1):38-44.

72. Bellando-Randone S, Matucci-Cerinic M. From Raynaud's phenomenon to very early diagnosis of systemic sclerosis- the VEDOSS approach. Curr Rheumatol Rev. 2013;9(4):245-8.

73. Camargo CZ, Sekiyama JY, Arismendi MI, Kayser C. Microvascular abnormalities in patients with early systemic sclerosis: less severe morphological changes than in patients with definite disease. Scand $J$ Rheumatol. 2015;44(1):48-55.

74. Ingegnoli F, Ardoino I, Boracchi P, Cutolo M. EUSTAR Co-authors. Nailfold capillaroscopy in systemic sclerosis: data from the EULAR scleroderma trials and research (EUSTAR) database. Microvasc Res. 2013;89:122-8.

75. Cutolo M, Sulli A, Smith V. Assessing microvascular changes in systemic sclerosis diagnosis and management. Nat Rev Rheumatol. 2010;6(10):578-87.

76. Bissell LA, Abignano G, Emery P, Del Galdo F, Buch MH. Absence of scleroderma pattern at nail fold capillaroscopy valuable in the exclusion of scleroderma in unselected patients with Raynaud's phenomenon. BMC Musculoskelet Disord. 2016;17(1):342.

77. Ingegnoli F, Zeni S, Meani L, Soldi A, Lurati A, Fantini F. Evaluation of nailfold videocapillaroscopic abnormalities in patients with systemic lupus erythematosus. J Clin Rheumatol. 2005;11(6):295-8.

78. Riccieri V, Spadaro A, Ceccarelli F, Scrivo R, Germano V, Valesini G. Nailfold capillaroscopy changes in systemic lupus erythematosus: correlations with disease activity and autoantibody profile. Lupus. 2005; 14(7):521-5.

79. Kuryliszyn-Moskal A, Ciolkiewicz M, Klimiuk PA, Sierakowski S. Clinical significance of nailfold capillaroscopy in systemic lupus erythematosus: correlation with endothelial cell activation markers and disease activity. Scand J Rheumatol. 2009;38(1):38-45.

80. Redisch W, Messina EJ, Hughes G, McEwen C. Capillaroscopic observations in rheumatic diseases. Ann Rheum Dis. 1970;29(3):244-53.

81. Altomonte L, Zoli A, Galossi A, Mirone L, Tulli A, Martone FR, Morini P, Laraia P, Magarò M. Microvascular capillaroscopic abnormalities in rheumatoid arthritis patients. Clin Exp Rheumatol. 1995:13(1):83-6.

82. Lambova SN, Müller-Ladner U. Capillaroscopic pattern in inflammatory arthritis. Microvasc Res. 2012;83(3):318-22.

83. Aslanidis S, Pyrpasopoulou A, Doumas M, Triantafyllou A, Chatzimichailidou S, Zamboulis C. Association of capillaroscopic microhaemorrhages with clinical and immunological antiphospholipid syndrome. Clin Exp Rheumatol. 2011:29(2):307-9.

84. Candela M, Pansoni A, De Carolis ST, Pomponio G, Corvetta A, Gabrielli A, Danieli G. Nailfold capillary microscopy in patients with antiphospholipid syndrome. Recenti Prog Med. 1998;89(9):444-9.

85. Sendino Revuelta A, Barbado Hernández FJ, Torrijos Eslava A, González Anglada I, Peña Sánchez de Rivera JM, Vázquez Rodríguez JJ. Capillaroscopy in vasculitis. An Med Interna. 1991;8(5):217-20.
86. Movasat A, Shahram F, Carreira PE, Nadji A, Akhlaghi M, Naderi N, Davatchi F. Nailfold capillaroscopy in Behçet's disease, analysis of 128 patients. Clin Rheumatol. 2009;28(5):603-5.

87. Tektonidou M, Kaskani E, Skopouli FN, Moutsopoulos HM. Microvascular abnormalities in Sjögren's syndrome: nailfold capillaroscopy. Rheumatology (Oxford). 1999;38(9):826-30.

88. Capobianco KG, Xavier RM, Bredemeier M, Restelli VG, Brenol JC. Nailfold capillaroscopic findings in primary Sjögren's syndrome: clinical and serological correlations. Clin Exp Rheumatol. 2005;23(6):789-94.

89. Silva I, Loureiro T, Teixeira A, Almeida I, Mansilha A, Vasconcelos C, et al. Digital ulcers in systemic sclerosis: role of flow-mediated dilatation and capillaroscopy as risk assessment tools. Eur J Dermatol. 2015;25(5):444-51.

90. Silva I, Teixeira A, Oliveira J, Almeida I, Almeida R, Águas A, Vasconcelos C. Endothelial dysfunction and Nailfold Videocapillaroscopy pattern as predictors of digital ulcers in systemic sclerosis: a cohort study and review of the literature. Clin Rev Allergy Immunol. 2015;49(2):240-52

91. Clements PJ, Lachenbruch PA, Furst DE, Maxwell M, Danovitch G, Paulus HE. Abnormalities of renal physiology in systemic sclerosis. A prospective study with 10-year followup. Arthritis Rheum. 1994;37(1):67-74.

92. Kinsella MB, Smith EA, Miller KS, LeRoy EC, Silver RM. Spontaneous production of fibronectin by alveolar macrophages in patients with scleroderma. Arthritis Rheum. 1989;32(5):577-83.

93. Clements PJ, Furst DE. Heart involvement in systemic sclerosis. Clin Dermatol. 1994;12(2):267-75

94. Grassi W, Core P, Carlino G, Cervini C. Acute effects of single dose nifedipine on cold-induced changes of microvascular dynamics in systemic sclerosis. Br J Rheumatol. 1994;33(12):1154-61.

95. Filaci G, Cutolo M, Scudeletti M, Castagneto C, Derchi L, Gianrossi R, Ropolo F, Zentilin P, Sulli A, Murdaca G, Ghio M, Indiveri F, Puppo F. Cyclosporin a and iloprost treatment of systemic sclerosis: clinical results and interleukin-6 serum changes after 12 months of therapy. Rheumatology (Oxford). 1999;38(10):992-6.

96. Amanzi L, Braschi F, Fiori G, Galluccio F, Miniati I, Guiducci S, et al. Digital ulcers in scleroderma: staging, characteristics and sub-setting through observation of 1614 digital lesions. Rheumatology (Oxford). 2010;49(7):1374-82.

97. Ferri C, Valentini G, Cozzi F, Sebastiani M, Michelassi C, La Montagna G, et al Systemic Sclerosis Study Group of the Italian Society of Rheumatology (SIRGSSSC). Systemic sclerosis: demographic, clinical, and serologic features and survival in 1,012 Italian patients. Medicine (Baltimore). 2002;81(2):139-53.

98. Silva I, Almeida C, Teixeira A, Oliveira J, Vasconcelos C. Impaired angiogenesis as a feature of digital ulcers in systemic sclerosis. Clin Rheumatol. 2016;35(7):1743-51.

99. Avouac J, Vallucci M, Smith V, Senet P, Ruiz B, Sulli A, et al. Correlations between angiogenic factors and capillaroscopic patterns in systemic sclerosis. Arthritis Res Ther. 2013;15(2):R55.

100. Farouk HM, Hamza SH, El Bakry SA, Youssef SS, Aly IM, Moustafa AA, Assaf NY, El Dakrony AH. Dysregulation of angiogenic homeostasis in systemic sclerosis. Int J Rheum Dis. 2013;16(4):448-54.

101. Lambova S, Müller-Ladner U. Capillaroscopic findings in systemic sclerosis are they associated with disease duration and presence of digital ulcers? Discov Med. 2011;12(66):413-8.

102. Silva I, Almeida J, Vasconcelos C. A PRISMA-driven systematic review for predictive risk factors of digital ulcers in systemic sclerosis patients. Autoimmun Rev. 2015;14(2):140-52.

103. Sebastiani M, Manfredi A, Colaci M, D'amico R, Malagoli V, Giuggioli D, Ferri C. Capillaroscopic skin ulcer risk index: a new prognostic tool for digital skin ulcer development in systemic sclerosis patients. Arthritis Rheum. 2009; 61(5):688-94.

104. Sebastiani M, Manfredi A, Vukatana G, Moscatelli S, Riato L, Bocci M, ludici M, Principato A, Mazzuca S, Del Medico P, De Angelis R, D'Amico R, Vicini R, Colaci $\mathrm{M}$, Ferri C. Predictive role of capillaroscopic skin ulcer risk index in systemic sclerosis: a multicentre validation study. Ann Rheum Dis. 2012:71(1):67-70.

105. Sebastiani M, Manfredi A, Colaci M, Giuggioli D, La Sala R, Elkhaldi N, Antonelli A, Ferri C. Correlation of a quantitative videocapillaroscopic score with the development of digital skin ulcers in scleroderma patients. Reumatismo. 2008;60(3):199-205.

106. Hofstee HM, Vonk Noordegraaf A, Voskuyl AE, Dijkmans BA, Postmus PE, et al. Nailfold capillary density is associated with the presence and severity of pulmonary arterial hypertension in systemic sclerosis. Ann Rheum Dis. 2009; 68(2):191-5

107. Ohtsuka T, Hasegawa A, Nakano A, Yamakage A, Yamaguchi M, Miyachi Y. Nailfold capillary abnormality and pulmonary hypertension in systemic sclerosis. Int J Dermatol. 1997;36(2):116-22. 
108. Bredemeier M, Xavier RM, Capobianco KG, Restelli VG, Rohde LE, et al. Capilaroscopia periungueal pode sugerir atividade de doença pulmonar na esclerose sistêmica. Rev Bras Reumatol. 2004;44(1):19-30.

109. Joyal F, Choquette D, Roussin A, Levington C, Senécal JL. Evaluation of the severity of systemic sclerosis by nailfold capillary microscopy in 112 patients. Angiology. 1992;43(3 Pt 1):203-10.

110. Smith V, Riccieri V, Pizzorni C, Decuman S, Deschepper E, Bonroy C, Sulli A, Piette Y, De Keyser F, Cutolo M. Nailfold capillaroscopy for prediction of novel future severe organ involvement in systemic sclerosis. J Rheumatol. 2013;40(12):2023-8.

111. Lovy M, MacCarter D, Steigerwald JC. Relationship between nailfold capillary abnormalities and organ involvement in systemic sclerosis. Arthritis Rheum. 1985;28(5):496-501.

112. Tolosa-Vilella C, Morera-Morales ML, Simeón-Aznar CP, Marí-Alfonso B, Colunga-Arguelles D, Callejas Rubio JL, et al. RESCLE Investigators, Autoimmune Diseases Study Group (GEAS). Digital ulcers and cutaneous subsets of systemic sclerosis: Clinical, immunological, nailfold capillaroscopy, and survival differences in the Spanish RESCLE Registry. Semin Arthritis Rheum. 2016;46(2):200-8.

113. Kayser C, Sekiyama JY, Próspero LC, Camargo CZ, Andrade LE. Nailfold capillaroscopy abnormalities as predictors of mortality in patients with systemic sclerosis. Clin Exp Rheumatol. 2013;31(2 Suppl 76):103-8.

114. Jadad AR, Moore RA, Carroll D, Jenkinson C, Reynolds DJ, Gavaghan DJ, et al. Assessing the quality of reports of randomized clinical trials: is blinding necessary? Control Clin Trials. 1996;17:1-12.

115. Goldet G, Howick J. Understanding GRADE: an introduction. J Evid Based Med. 2013;6:50-4

116. Wells G, Shea B, O'Connell D, Robertson J, Peterson J, Welch V, et al. The Newcastle-Ottawa Scale (NOS) for assessing the quality of nonrandomised studies in meta-analyses.

117. Levels of Evidence and Grades of Recommendations - Oxford Centre for Evidence Based Medicine. http://www.cebm.net/index.aspx?o=5653.

Ready to submit your research? Choose BMC and benefit from:

- fast, convenient online submission

- thorough peer review by experienced researchers in your field

- rapid publication on acceptance

- support for research data, including large and complex data types

- gold Open Access which fosters wider collaboration and increased citations

- maximum visibility for your research: over $100 \mathrm{M}$ website views per year

At $\mathrm{BMC}$, research is always in progress.

Learn more biomedcentral.com/submissions 